\title{
Effect of Sampling Regime on Estimation of Basal Metabolic Rate and Standard Evaporative Water Loss Using Flow-Through Respirometry
}

\author{
C. E. Cooper ${ }^{\star}$ \\ P. C. Withers \\ Centre for Ecosystem Diversity and Dynamics in the \\ Department of Environmental and Aquatic Sciences, Curtin \\ University of Technology, P.O. Box U1987, Perth, Western \\ Australia 6845, Australia; and School of Animal Biology, \\ University of Western Australia, Crawley, Western Australia \\ 6009, Australia
}

Accepted 6/28/2009; Electronically Published 2/1/2010

\begin{abstract}
Strict criteria have been established for measurement of basal metabolic rate and standard evaporative water loss to ensure that data can be compared intra- and interspecifically. However, data-sampling regimes vary, from essentially continuous sampling to interrupted (switching) systems with data recorded periodically at more widely spaced intervals. Here we compare one continuous and three interrupted sampling regimes to determine whether sampling regime has a significant effect on estimation of basal metabolic rate or standard evaporative water loss. Compared to continuous 20-s sampling averaged over 20 min, sampling every $6 \mathrm{~min}$ and averaging over $60 \mathrm{~min}$ overestimated basal metabolic rate and evaporative water loss, sampling every $3 \mathrm{~min}$ and averaging over $21 \mathrm{~min}$ underestimated basal metabolic rate, and sampling every $12 \mathrm{~min}$ and averaging over 36 min showed no difference in estimates. Increasing the period over which the minimum mean was calculated significantly increased estimates of physiological variables. Reducing the frequency of sampling from $20 \mathrm{~s}$ to a longer interval of 3 , 6 , or 12 min underestimated basal metabolic rate but not evaporative water loss. This indicates that sampling frequency per se influences estimates of basal metabolic rate and that differences are not just an artifact of differences in the period over which the mean is calculated. Sampling regime can have a highly significant influence on estimation of standard physiological variables, although the actual differences between sampling regimes were generally small (usually $<5 \%$ ). Although continuous sampling is the preferred sampling regime for open-
\end{abstract}

\footnotetext{
*Corresponding author; e-mail: c.cooper@curtin.edu.au.
}

Physiological and Biochemical Zoology 83(2):385-393. 2010. (C) 2010 by The University of Chicago. All rights reserved. 1522-2152/2010/8302-9060\$15.00 DOI: $10.1086 / 605612$ flow respirometry studies, if time and cost are prohibitive, then use of an appropriate switching system will result in smaller errors than measuring individuals continuously for shorter periods.

\section{Introduction}

Basal metabolic rate (BMR) is one of the most commonly measured physiological variables for birds and mammals. Usually, it is determined by indirect calorimetry, where the rate of either oxygen consumption $\left(\dot{\mathrm{V}}_{\mathrm{O}_{2}}\right)$ or carbon dioxide production $\left(\dot{\mathrm{V}}_{\mathrm{CO}_{2}}\right)$ is measured. These can then be converted to units of heat production/energy consumption by the chemical stoichiometry of metabolism (i.e., using the respiratory quotient; see Withers 1992 for conversions). A wide variety of techniques can be used to measure $\dot{\mathrm{V}}_{2}$ and $\dot{\mathrm{V}}_{\mathrm{CO}_{2}}$, including manometry, closed-system respirometry, and, most commonly, open-flow respirometry. Open-flow respirometry is the most reliable of these techniques because it can reduce errors associated with ambient temperature $\left(T_{\mathrm{a}}\right)$ or pressure fluctuations and allows for long periods of continuous measurement so that intermittent periods of animal activity can be accounted for. Standard evaporative water loss (or SEWL, evaporative water loss at or near the lower critical temperature of the thermoneutral zone) is another commonly measured standardized physiological variable that can be measured by respirometry (hygrometry). SEWL is often measured in an open-flow respirometry system, simultaneously with $\mathrm{MR}$, to determine the evaporative component of heat loss.

One of the major objectives of measuring BMR and SEWL is to obtain standardized measures of energy and water use that can be used for intra- and interspecific comparisons. Therefore, strict criteria have been established to ensure that these data are comparable; that is, subjects must be adult, nonreproductive, postabsorptive, endothermic individuals measured during the inactive phase of their circadian rhythm, at rest within their thermoneutral zone while euthermic (McNab 1997; IUPS Thermal Commission 2003; Cooper and Withers 2009). There are various descriptions of system design, calibration, and calculation for open-flow respirometry (Depocas and Hart 1957; Lasiewski et al. 1966; Hill 1972; Withers 1977, 2001; Koteja 1996; Lighton 2008), along with quantification of the effects of miscalculation or calibration (see Withers 2001). Effects of variation in other aspects of experimental design and analysis on the estimation of BMR and SEWL have also been investigated, 
for example, chamber relative humidity (RH; Lasiewski et al. 1966; Cooper and Withers 2008), experimental duration (Gallivan 1992; Hayes et al. 1992; Cooper and Withers 2009), flow rate (McNab 2006), sample size (McNab 2003), use of chemical desiccants (Elia et al. 1986; White et al. 2006), and time period over which mean values are calculated (Hayes et al. 1992; Withers 2001). However, another factor that potentially affects the estimation of these standard physiological variables is sampling protocol, including the frequency and pattern of sampling (e.g., use of a switching system).

Sampling frequency (i.e., the interval at which data points are recorded) of excurrent gas composition in open-flow systems can be essentially continuous at a relatively high frequency, for example, every $5 \mathrm{~s}$ to $1 \mathrm{~min}$ (Chappell and Roverud 1990; Walsberg and Wolf 1995; Merola-Zwartjes 1998; Dawson et al. 2000; Larcombe 2002; Cooper et al. 2009; Withers and Cooper 2009), or it can be considerably slower, for example, 3 to 12 min (if, e.g., the respirometry system switches between a number of animals or room air; Song and Geiser 1997; McKechnie and Lovegrove 1999, 2001; Holloway and Geiser 2001; Downs and Brown 2002; Bush et al. 2008; Doucette and Geiser 2008). Sometimes a combination is used, with essentially continuous data recorded at a high frequency for a specific period of time (e.g., every 1-5 s for 1.3-12 min) before switching to another animal or room air (Buttemer and Astheimer 2000; Newman et al. 2002; Boratyński and Koteja 2009). Continuous highfrequency sampling requires a complete respirometry system (i.e., flowmeter, metabolic chamber, and gas analyzers) for each experimental subject; thus, only one individual can be measured at a time with a single system. To obtain a statistically viable sample size (usually six to eight individuals) of truly resting animals (which requires long experimental periods; Cooper and Withers 2009) in their inactive phase requires either extended study durations (especially if a range of $T_{\mathrm{a}}$ 's are being examined; for example, approximately a week per $T_{\mathrm{a}}$ ) or the concomitant use of multiple complete respirometry systems, which is costly. Alternatively, one set of gas analyzers can be used to measure several animals simultaneously (and often a control ambient air sample), by sequentially sampling excurrent air from a series of metabolism chambers in turn through the analyzers. However, use of such a switching system necessarily results in an interrupted sampling regime, as each animal's chamber excurrent air must be passed through the analyzer in turn. The interval between samples will depend on the number of animals being measured, the washout characteristics of the metabolic systems, and the response time of the analyzers.

Hayes et al. (1992) compared BMR calculated from data collected for $15 \mathrm{~min}$ every hour for $6 \mathrm{~h}$ to that calculated from data collected continuously (5-s interval) for $90 \mathrm{~min}$. They found that for short-tailed field voles (Microtus agrestis) there was no difference in estimates of BMR, but for wood mice (Apodemus sylvaticus), interrupted sampling produced BMRs $18 \%$ lower than those from the continuous 90 -min sample. However, their analysis compared different experimental time courses (90 min and $6 \mathrm{~h}$ ) and for wood mice was restricted to a sample size of two individuals. Here we compare a high- frequency sampling regime with three regimes of lowerfrequency sampling, simulating interrupted sampling, over equivalent measurement durations for seven species of marsupial, to quantify any differences in measurement of BMR and SEWL.

\section{Material and Methods}

Thermoneutral $\dot{\mathrm{V}}_{2}, \dot{\mathrm{V}}_{\mathrm{CO}_{2}}$, and EWL were measured for seven species of marsupial: common dunnart (Sminthopsis murina; $10.4 \mathrm{~g}, N=7$ ), little red kaluta (Dasykaluta rosamondae; 35.5 g, $N=7$ ), gracile mouse opossum (Gracilinanus agilis; $31 \mathrm{~g}$, $N=6\left[N=5\right.$ for $\left.\dot{\mathrm{V}} \mathrm{CO}_{2}\right]$ ), squirrel glider (Petaurus norfolcensis; $196 \mathrm{~g}, N=7$ ), eastern quoll (Dasyurus viverinus; $874 \mathrm{~g}, N=$ 6), brushtail possum (Trichosurus vulpecula; 2,068 g, $N=6$ ), and tiger quoll (Dasyurus hallucatus; $3,373 \mathrm{~g}, \mathrm{~N}=6$ ). Standard open-flow respirometry was used to measure $\dot{\mathrm{V}}_{2}, \dot{\mathrm{V}}_{\mathrm{CO}_{2}}$, and EWL, as described for the kaluta and mouse opossums by Withers and Cooper (2009) and Cooper et al. (2009), respectively. Measurements for the other species followed the same general protocols, although some equipment varied. The excurrent fractional $\mathrm{O}_{2}$ and $\mathrm{CO}_{2}$ and the $\mathrm{RH}$ were recorded for all species every 10-20 s for experiments lasting $>6 \mathrm{~h}$, and calculations of $\dot{\mathrm{V}}_{2}, \dot{\mathrm{V}}_{2}\left(\mathrm{~mL} \mathrm{O}_{2} / \mathrm{CO}_{2} \mathrm{~g}^{-1} \mathrm{~h}^{-1}\right)$, and EWL (mg $\mathrm{H}_{2} \mathrm{O} \mathrm{g}^{-1} \mathrm{~h}^{-1}$ ) followed Withers (2001) and used custom-written Visual Basic software (VB, ver. 6).

To simulate different sampling regimes, the continuously measured $\dot{\mathrm{V}}_{2}, \dot{\mathrm{V}}_{\mathrm{CO}_{2}}$, and EWL data for each species were subsampled, starting at the first data point and then skipping the appropriate number of data points to obtain values at 20-s, 3min, 6-min, and 12-min intervals. These simulated sampling intervals represented continuous (20 s; Cooper et al. 2009; Withers and Cooper 2009) and three interrupted sampling regimes described in the literature $(3 \mathrm{~min}$ : Doucette and Geiser 2008; 6 min: Downs and Brown 2002; Bush et al. 2008; 12 min: Maddocks and Geiser 1997; Song and Geiser 1997; Holloway and Geiser 2001). For each of these sampling regimes, the mean minimum $\dot{\mathrm{V}}_{2}, \dot{\mathrm{V}}_{\mathrm{CO}_{2}}$, and EWL were determined as the mean of the values collected over the period of time specified in the literature for each of the selected sampling regimes $(20 \mathrm{~min}$ for 20-s sampling, i.e., 60 data points; $21 \mathrm{~min}$ for 3-min sampling, i.e., seven data points; $60 \mathrm{~min}$ for 6 -min sampling, i.e., 10 data points; and $36 \mathrm{~min}$ for 12-min sampling, i.e., three data points).

Any differences between these sampling regimes could be attributed to differences in the time period over which the mean minimum was calculated (i.e., 20, 21, 30, or $60 \mathrm{~min}$ ) or to differences in sampling frequency (i.e., every $20 \mathrm{~s}, 3 \mathrm{~min}, 6$ $\mathrm{min}$, or $12 \mathrm{~min}$ ). Therefore, two further analyses were conducted. Mean minimal values were calculated for the 20-s continuously sampled data, for the continuous averaging period (20 $\mathrm{min}$ ), and for each of interrupted averaging periods (21, 36 , and $60 \mathrm{~min}$ ) to quantify the effect of averaging period. Thus, the averaging period was varied, but the sampling frequency remained constant. We also calculated the variance of the data during each averaging period and examined the relationship between the difference between the 20-min average 
and the 21-, 36-, and 60-min averages and the variance. Then, the averaging period was held constant and the sampling frequency was varied; 20-s sampling was compared with 3-min sampling (with the average calculated over $21 \mathrm{~min}$ for both), then with 6-min sampling (and the average calculated over 60 min for both), and finally with 12-min sampling (and the average calculated over $36 \mathrm{~min}$ for both).

Simulations of each sampling regime were accomplished by subsampling the original continuous data using a custom-written VB program. Comparison of the different sampling regimes was made using repeated-measures ANOVA (RMANOVA), with species as a factor. As post hoc tests are unavailable for RMANOVA, the differences between specific sampling regimes had to be identified by removing each regime in turn and determining when the RMANOVA was no longer significant (Rencher 1995). The relationship between the variance of the data and the difference resulting from varying the averaging period was determined by regression. All statistical analyses used statistiXL (http://www .statistixl.com/).

\section{Results}

\section{Oxygen Consumption}

Sampling regime had a significant effect on the mean minimum $\dot{\mathrm{V}}_{\mathrm{O}_{2}}\left(F_{3,36}=6.23, P=0.002\right)$, and there was a significant effect of species $\left(F_{6,38}=26.1, P<0.001\right)$. There was no significant interaction between species and sampling regime $\left(F_{18,102}=1.35\right.$, $P=0.176)$. Removal of various regimes from the RMANOVA model indicated that the 6-min interval averaged over a 60 -min regime $(6 \mathrm{~min} / 60 \mathrm{~min}$ ) and the 3-min interval averaged over a 21-min regime $(3 \mathrm{~min} / 21 \mathrm{~min}$ ) yielded estimates of minimal $\dot{\mathrm{V}}_{2}$ significantly different from those under the continuous sampling regime, but the 12-min sampling regime averaged over 36 $\min (12 \mathrm{~min} / 36 \mathrm{~min}$ ) did not (Table 1). The 3-min/21-min regime underestimated BMR $(98.9 \% \pm 0.3 \%$ of the continuoussampling-regime mean for all species), whereas the 6-min/60min regime overestimated BMR $(107.8 \% \pm 1.83 \%)$. To determine whether these differences between sampling regimes resulted from differences in the period over which the mean minimum was calculated or from the different sampling interval, each of these effects was examined separately.

Averaging period had a significant effect on the mean minimum $\dot{V}_{\mathrm{O}_{2}}\left(F_{3,36}=8.28, P<0.001\right)$ for all species. For data recorded every $20 \mathrm{~s}$, the mean calculated over $20 \mathrm{~min}$ was significantly lower $(P \leq 0.002)$ than those calculated over all other periods $(21,36$, or $60 \mathrm{~min}$; Table 2$)$. There was also a significant effect of species $\left(F_{7,38}=3,375, P<0.001\right)$ but no interaction $\left(F_{18,102}=1.69, P=0.053\right)$. The difference between the 20-min mean and the 36- and 60-min means was significantly related to the variance of the $36-$ and $60-\mathrm{min}$ minimum periods, respectively $\left(F_{1,43}=218, P<0.001 ; F_{1,43}=84, P<\right.$ 0.001 ), but this relationship was not significant for the 21-min period $\left(F_{1,43}=0.194, P=0.662\right)$.

Each interrupted sampling regime (3, 6, and $12 \mathrm{~min}$ ) was compared separately to the continuous sampling regime (20 s), with the mean for both interrupted and continuous samples taken over the same period as described in the literature for that interrupted regime (e.g., $21 \mathrm{~min}$ for the 3-min, $36 \mathrm{~min}$ for the 12-min, and $60 \mathrm{~min}$ for the 6-min comparison). All interrupted sampling regimes significantly underestimated $\dot{\mathrm{V}}_{2}$, compared with continuous (20-s) sampling, when both interrupted and continuous data were averaged over the same period (3-min interval: $F_{1,38}=14.0, P=0.001$; 6-min sampling: $F_{1,38}=11.6, P=0.002 ; 12-\min$ sampling: $F_{1,38}=4.39$, $P=0.043$; Table 3).

\section{Carbon Dioxide Production}

Species $\left(F_{6,37}=10.01, \quad P<0.001\right)$ and sampling regime $\left(F_{3,35}=4.32, P=0.011\right)$ had significant effects on $\dot{\mathrm{V}} \mathrm{CO}_{2}$, with no significant interaction term $\left(F_{18,99}=1.32, P=0.193\right)$. Removal of various regimes from the RMANOVA model indicated that the 6-min/60-min regime differed from the other regimes, with consistently higher estimates of $\dot{\mathrm{V}} \mathrm{CO}_{2}$ (Table 1).

Both the period over which the mean was taken $\left(F_{3,35}=\right.$ 7.82, $P<0.001)$ and species $\left(F_{6,37}=9.60, P<0.001\right)$ had significant effects on $\dot{\mathrm{V}}_{\mathrm{CO}_{2}}$, and there was no interaction $\left(F_{18,99}=1.25, P=0.236\right)$. The mean taken over $20 \mathrm{~min}$ was significantly lower $(P \leq 0.015)$ than all other means (Table 2$)$. The differences between the 20-min mean and the 36- and 60min means were significantly related to the variance of the 36and 60-min minimum periods, respectively $\left(F_{1,43}=1,050\right.$, $\left.P<0.001 ; F_{1,43}=244, P<0.001\right)$, but this was not the case for the 21-min mean $\left(F_{1,43}<0.001, P=0.998\right)$.

Comparison of each interrupted sampling regime $(3,6$, and $12 \mathrm{~min})$ separately to a continuous sample (20 s) with the mean taken over the same period for interrupted and continuous data indicated that all interrupted sampling regimes significantly underestimated $\dot{\mathrm{V}}_{\mathrm{CO}_{2}}$ when compared with continuous (20-s) sampling (3-min interval: $F_{1,37}=6.21, P=0.017$; 6-min interval: $F_{1,37}=5.11, P=0.030 ; 12$-min interval: $F_{1,37}=8.20$, $P=0.007$; Table 3). There were significant differences between species for all three analyses $(P<0.001)$.

\section{Evaporative Water Loss}

Both sampling regime $\left(F_{3,36}=10.8, P<0.001\right)$ and species $\left(F_{6,38}=1.15, P<0.001\right)$ had significant effects on SEWL. There was no significant interaction between these variables $\left(F_{18,192}=1.14, P=0.320\right)$. Removal of various regimes from the RMANOVA model indicated that the 6-min/60-min-mean regime differed from the others by having consistently higher estimates of EWL (Table 1).

The period over which the mean was calculated $(20,21,36$, or $60 \mathrm{~min}$ ) for continuously (20 s) sampled data had an effect on the calculated SEWL $\left(F_{3,36}=18.8, P<0.001\right.$; Table 2$)$. The effect of species $\left(F_{6,38}=15.8, P<0.001\right)$ was also significant, and there was no significant interaction term $\left(F_{18,102}=1.31\right.$, $P=0.196)$. The mean taken over $20 \mathrm{~min}$ was significantly lower $(P \leq 0.013)$ than all other means (Table 2$)$. The differences between the 20-min mean and the 21-, 36-, and 60-min means were significantly related to the variances of the 21-, 
Table 1: Effect of sampling regime on the estimation of oxygen consumption $\left(\dot{\mathrm{V}}_{2}\right)$, carbon dioxide production $\left(\dot{\mathrm{V}} \mathrm{CO}_{2}\right)$, and evaporative water loss $(\mathrm{EWL})$ for seven species of marsupial

\begin{tabular}{|c|c|c|c|c|}
\hline \multirow[b]{2}{*}{ Species } & \multicolumn{4}{|c|}{$\begin{array}{l}\text { Sampling Regime } \\
\text { (\% of } 20-\mathrm{s} / 20-\mathrm{min} \text { Regime Mean) }\end{array}$} \\
\hline & \multicolumn{2}{|c|}{$3 \mathrm{~min} / 21 \mathrm{~min}$} & $6 \mathrm{~min} / 60 \mathrm{~min}$ & $12 \mathrm{~min} / 36 \mathrm{~min}$ \\
\hline \multicolumn{5}{|l|}{$\dot{\mathrm{V}}_{2}:$} \\
\hline Common dunnart & 98.0 & .70 & $112.6 \pm$ & $104.2 \pm$ \\
\hline Gracile mouse opossum & 99.1 & .68 & $104.0 \pm 1.62$ & $99.3 \pm 2.34$ \\
\hline Little red kaluta & 97.8 & 1.17 & $109.0 \pm 25.5$ & $103.2 \pm 11.26$ \\
\hline Squirrel glider & 99.4 & .36 & $104.5 \pm .65$ & $99.7 \pm 1.18$ \\
\hline Eastern quoll & 99.0 & 1.09 & $115.6 \pm$ & $102.2 \pm$ \\
\hline Brushtail possum & 99.5 & \pm 11.6 & $105.8 \pm$ & $101.7 \pm$ \\
\hline Tiger quoll & 99.6 & \pm .21 & $102.8 \pm$ & $101.0 \pm$ \\
\hline Mean & 98.98 & $.3^{\mathrm{a}}$ & $107.8 \pm$ & $99.8 \pm$ \\
\hline \multicolumn{5}{|l|}{$\dot{\mathrm{V}}_{\mathrm{CO}_{2}}:$} \\
\hline Common dunnart & 98.3 & .87 & $108.1 \pm$ & $100.3 \pm$ \\
\hline Gracile mouse opossum & 99.3 & .31 & $102.8 \pm$ & $99.0 \pm$ \\
\hline Little red kaluta & 101.0 & 1.71 & $107.8 \pm$ & $97.8 \pm$ \\
\hline Squirrel glider & 98.9 & .63 & $105.9 \pm$ & $102.0 \pm$ \\
\hline Eastern quoll & 99.2 & .41 & $107.6 \pm$ & $95.7 \pm$ \\
\hline Brushtail possum & 99.1 & .63 & $105.9 \pm$ & $101.5 \pm$ \\
\hline Tiger quoll & 100.3 & .19 & $105.0 \pm$ & $102.9 \pm$ \\
\hline Mean & 99.6 & .4 & $106.4 \pm$ & $100.0 \pm$ \\
\hline \multicolumn{5}{|l|}{ EWL: } \\
\hline Common dunnart & 100.2 & .73 & $116.4 \pm$ & $110.3 \pm$ \\
\hline Gracile mouse opossum & 99.9 & .76 & $108.0 \pm$ & $104.8 \pm$ \\
\hline Little red kaluta & 98.1 & .85 & $111.7 \pm$ & $103.0 \pm$ \\
\hline Squirrel glider & 100.0 & .27 & $114.3 \pm$ & $110.2 \pm$ \\
\hline Eastern quoll & 101.1 & 7.10 & $111.0 \pm$ & $101.3 \pm$ \\
\hline Brushtail possum & 99.8 & .72 & $111.0 \pm$ & $106.4 \pm$ \\
\hline Tiger quoll & 100.0 & .29 & $107.4 \pm$ & $102.7 \pm$ \\
\hline Mean & 99.9 & .4 & $112.1 \pm$ & $105.7 \pm$ \\
\hline
\end{tabular}

Note. Regimes are continuous 20-s sampling and minimum 20-min average (20 s/20 min), 3-min sampling interval and minimum 21-min average ( $3 \mathrm{~min} / 21 \mathrm{~min}$ ), 6-min sampling interval and minimum $60-\mathrm{min}$ average $(6 \mathrm{~min} / 60 \mathrm{~min})$, and $12-\mathrm{min}$ sampling interval and minimum 36-min average $(12 \mathrm{~min} /$ $36 \mathrm{~min})$. Values are mean $\pm \mathrm{SE}$.

${ }^{a}$ Indicates a significant difference from results under the 20-s/20-min regime.

36-, and 60-min minimum periods (respectively, $F_{1,44}=411$, $\left.P<0.001 ; F_{1,44}=1,238, P<0.001 ; F_{1,44}=789, P<0.001\right)$.

An intermittent sampling regime of 3,6 , or $12 \mathrm{~min}$ did not significantly affect the estimation of SEWL compared with a continuous (20-s) regime when each was compared separately with a continuous sample with the mean taken over the same period (i.e., 21,60 , or 36 , respectively; 3 -min interval: $F_{1,38}=$ 3.85, $P=0.057$; 6-min interval: $F_{1,39}=1.00, P=0.324 ; 12$ min interval: $\left.F_{1,39}=0.24, P=0.627\right)$. There were significant differences between species for all three analyses $(P<0.001)$.

\section{Discussion}

A wide variety of sampling regimes are used for flow-through respirometry. Here we examined an essentially continuous and three interrupted sampling regimes, representing a range of the more varied sampling intervals and calculation periods used in the literature, to determine the effect that variation in sampling regime may have on the estimation of BMR (measured as both $\dot{\mathrm{V}}_{2}$ and $\dot{\mathrm{V}}_{\mathrm{CO}_{2}}$ ) and SEWL. We found that sampling regime significantly influences the estimation of these standard physiological variables, and although these effects are generally small, they should be considered when designing sampling regimes for respirometry and when interpreting existing data.

Significant differences were found between species for $\dot{\mathrm{V}}_{2}$, $\dot{\mathrm{V}} \mathrm{CO}_{2}$, and EWL in all analyses. This between-species variation was expected because of the $>30$-fold range in body mass of the species investigated (from $10.4 \mathrm{~g}$ for common dunnarts to $3,373 \mathrm{~g}$ for tiger quolls) and the highly significant allometric effect on BMR and SEWL for marsupials (McNab 2005; Withers et al. 2006) and indeed all animals (Kleiber 1932; Hemmingsen 
Table 2: Effect of period (20, 21, 36, or $60 \mathrm{~min}$ ) over which the mean minimum oxygen consumption $\left(\dot{\mathrm{V}}_{2}\right)$, carbon dioxide production $\left(\dot{\mathrm{V}}_{\mathrm{CO}_{2}}\right)$, and evaporative water loss (EWL) were calculated, for data sampled at 20-s intervals from seven species of marsupial

\begin{tabular}{|c|c|c|c|}
\hline \multirow[b]{2}{*}{ Species } & \multicolumn{3}{|c|}{ Period of Mean ( $\%$ of $20-$ min Mean) } \\
\hline & $21 \mathrm{~min}$ & $36 \min$ & $60 \mathrm{~min}$ \\
\hline \multicolumn{4}{|l|}{$\dot{\mathrm{V}}_{\mathrm{O}_{2}}$} \\
\hline Common dunnart & $100.6 \pm .03$ & $109.8 \pm 3.92$ & $114.8 \pm 6.00$ \\
\hline Gracile mouse opossum & $100.2 \pm .08$ & $103.4 \pm 1.48$ & $106.2 \pm 1.89$ \\
\hline Little red kaluta & $100.1 \pm .14$ & $105.5 \pm 1.84$ & $121.2 \pm 9.77$ \\
\hline Squirrel glider & $100.3 \pm .06$ & $102.7 \pm .73$ & $105.7 \pm .74$ \\
\hline Eastern quoll & $100.1 \pm .09$ & $108.6 \pm 4.41$ & $113.3 \pm 5.13$ \\
\hline Brushtail possum & $100.3 \pm .07$ & $103.9 \pm 1.06$ & $105.9 \pm 1.33$ \\
\hline Tiger quoll & $100.1 \pm .03$ & $101.7 \pm .69$ & $103.7 \pm .93$ \\
\hline Mean & $100.3 \pm .07^{\mathrm{a}}$ & $104.6 \pm 1.05^{\mathrm{a}}$ & $109.5 \pm 2.27^{\mathrm{a}}$ \\
\hline \multicolumn{4}{|l|}{$\dot{\mathrm{V}} \mathrm{CO}_{2}:$} \\
\hline Common dunnart & $100.5 \pm .23$ & $107.4 \pm 2.73$ & $109.6 \pm 2.99$ \\
\hline Gracile mouse opossum & $100.3 \pm .16$ & $102.1 \pm .30$ & $103.0 \pm .61$ \\
\hline Little red kaluta & $100.3 \pm .27$ & $103.1 \pm .72$ & $110.3 \pm 3.42$ \\
\hline Squirrel glider & $100.2 \pm .12$ & $103.8 \pm .83$ & $106.1 \pm .82$ \\
\hline Eastern quoll & $100.2 \pm .07$ & $104.0 \pm 1.31$ & $108.8 \pm 2.62$ \\
\hline Brushtail possum & $100.2 \pm .12$ & $103.2 \pm 1.09$ & $106.5 \pm 1.75$ \\
\hline Tiger quoll & $100.2 \pm .08$ & $102.4 \pm .63$ & $105.0 \pm 1.52$ \\
\hline Mean & $100.3 \pm .07^{\mathrm{a}}$ & $103.9 \pm .97^{\mathrm{a}}$ & $107.2 \pm 1.2^{\mathrm{a}}$ \\
\hline \multicolumn{4}{|l|}{ EWL: } \\
\hline Common dunnart & $100.5 \pm .29$ & $110.1 \pm 6.11$ & $114.8 \pm 7.31$ \\
\hline Gracile mouse opossum & $100.2 \pm .12$ & $104.1 \pm 1.03$ & $107.9 \pm 2.38$ \\
\hline Little red kaluta & $100.7 \pm .29$ & $105.9 \pm 2.01$ & $111.7 \pm 2.39$ \\
\hline Squirrel glider & $100.4 \pm .19$ & $109.3 \pm 3.93$ & $113.0 \pm 3.93$ \\
\hline Eastern quoll & $100.3 \pm .16$ & $103.9 \pm 1.20$ & $110.8 \pm 1.61$ \\
\hline Brushtail possum & $100.4 \pm .21$ & $105.9 \pm 1.63$ & $112.0 \pm 1.39$ \\
\hline Tiger quoll & $100.3 \pm .05$ & $103.6 \pm .96$ & $107.8 \pm 1.40$ \\
\hline Mean & $100.4 \pm .06^{\mathrm{a}}$ & $106.5 \pm 1.39^{\mathrm{a}}$ & $111.4 \pm 1.41^{\mathrm{a}}$ \\
\hline
\end{tabular}

Note. Values are mean \pm SE.

${ }^{\text {a }}$ Indicates a significant difference from results with a 20 -min mean.

1950; Schmidt-Nielsen 1984; Withers 1992). Species used for this study were selected to provide a variation in body mass, ensuring that the results were not restricted to a limited mass range, because potential differences in activity during measurements or chamber dynamics for large and small species could possibly influence the results. However, an absence of significant interactions between sampling regime and species indicates that sampling regime had similar effects on the estimation of BMR and SEWL for all species.

Switching systems for simultaneous measurement of multiple animals by open-flow respirometry provide obvious time and cost benefits but necessitate a low-frequency or interrupted sampling regime. However, switching systems are useful only if the interrupted sampling regime provides an estimate of $\dot{\mathrm{V}}_{\mathrm{O}_{2}}, \dot{\mathrm{V}}_{\mathrm{CO}_{2}}$, and EWL equivalent to that under a continuous sampling regime. Thus, quantitative analysis of potential measurement bias resulting from noncontinuous sampling is necessary both to interpret existing data obtained using noncon- tinuous sampling and for future experimental design. The four sampling regimes that we selected from the literature for analysis were representative of a wide array of actual and potential sampling regimes. These were chosen to provide comparison of an essentially continuous regime (20 s/20 min) with a shortinterval, short-minimum-mean regime $(3 \mathrm{~min} / 21 \mathrm{~min}$; Doucette and Geiser 2008), an intermediate-interval, long-minimum-mean regime (6 min/60 min; Downs and Brown 2002; Bush et al. 2008), and a long-interval, intermediate-minimummean period regime (12 min/36 min; Maddocks and Geiser 1997; Song and Geiser 1997; Holloway and Geiser 2001).

We found a significant effect for these sampling regimes on the estimation of $\mathrm{BMR}$, measured as $\dot{\mathrm{V}}_{2}$ and $\dot{\mathrm{V}}_{\mathrm{CO}_{2}}$, and on EWL (Table 1). The 6-min/60-min regime overestimated all three physiological variables, compared with a $20-\mathrm{s} / 20$-min regime, whereas the 3-min/21-min regime underestimated $\dot{\mathrm{V}}_{2}$; estimates from the $12-\mathrm{min} / 36-\mathrm{min}$ regime did not differ from those under the 20-s/20-min regime. These differences between 
Table 3: Effect of sampling frequency (3-, 6-, or 12-min intervals) compared with continuous sampling (20-s intervals) on the calculated oxygen consumption $\left(\dot{\mathrm{V}}_{2}\right)$, carbon dioxide production $\left(\dot{\mathrm{V}}_{\mathrm{CO}_{2}}\right)$, and evaporative water loss (EWL) for seven species of marsupial

\begin{tabular}{|c|c|c|c|c|}
\hline \multirow[b]{2}{*}{ Species } & \multicolumn{4}{|c|}{$\begin{array}{l}\text { Sampling Interval } \\
\text { (\% of Continuous-Sampling Mean) }\end{array}$} \\
\hline & $3 \min$ & $6 \mathrm{~min}$ & $12 \mathrm{~min}$ & \\
\hline \multicolumn{5}{|l|}{$\dot{\mathrm{V}}_{2}:$} \\
\hline Common dunnart & $97.4 \pm$ & $98.2 \pm 1.40$ & 95.0 & \pm 1.41 \\
\hline Gracile mouse opossum & $98.9 \pm$ & $98.0 \pm 1.11$ & 96.2 & \pm 3.16 \\
\hline Little red kaluta & $99.0 \pm 1.08$ & $96.7 \pm 2.36$ & 96.4 & \pm 3.09 \\
\hline Squirrel glider & $99.1 \pm .35$ & $98.9 \pm .35$ & 97.1 & \pm 1.29 \\
\hline Eastern quoll & $97.7 \pm .97$ & $100.5 \pm 1.39$ & 94.1 & \pm 6.90 \\
\hline Brushtail possum & $99.2 \pm 1.02$ & $99.8 \pm .81$ & 98.3 & \pm 1.34 \\
\hline Tiger quoll & $99.5 \pm .20$ & $99.2 \pm .28$ & 99.4 & \pm .82 \\
\hline Mean & $98.7 \pm$ & $98.7 \pm .35^{\mathrm{a}}$ & 95.3 & $\pm 1.5^{\mathrm{a}}$ \\
\hline \multicolumn{5}{|l|}{$\dot{\mathrm{V}}_{\mathrm{CO}_{2}}:$} \\
\hline Common dunnart & $97.8 \pm$ & $98.6 \pm 1.40$ & 93.7 & \pm 2.30 \\
\hline Gracile mouse opossum & $99.0 \pm .29$ & $99.9 \pm 1.11$ & 97.0 & \pm .47 \\
\hline Little red kaluta & $101.1 \pm 1.47$ & $98.4 \pm 1.09$ & 94.6 & \pm 2.23 \\
\hline Squirrel glider & $98.7 \pm .71$ & $99.8 \pm .56$ & 98.3 & \pm 1.15 \\
\hline Eastern quoll & $99.0 \pm$ & $99.0 \pm .70$ & 92.0 & \pm 5.32 \\
\hline Brushtail possum & $98.9 \pm$ & $99.5 \pm 1.17$ & 98.3 & \pm 1.77 \\
\hline Tiger quoll & $100.1 \pm$ & $100.0 \pm .17$ & 100.5 & \pm 1.31 \\
\hline Mean & $99.3 \pm$ & $99.4 \pm$ & 96.3 & $\pm 1.22^{\mathrm{a}}$ \\
\hline \multicolumn{5}{|l|}{ EWL: } \\
\hline Common dunnart & $99.7 \pm$ & $100.8 \pm 1.20$ & 99.8 & \pm 1.50 \\
\hline Gracile mouse opossum & $99.7 \pm$ & $100.7 \pm .86$ & 100.6 & \pm 6.75 \\
\hline Little red kaluta & $97.5 \pm$ & $100.7 \pm .93$ & 96.8 & \pm 2.78 \\
\hline Squirrel glider & $99.6 \pm$ & $101.1 \pm 1.15$ & 101.1 & \pm 2.57 \\
\hline Eastern quoll & $100.0 \pm$ & $99.7 \pm 1.14$ & 97.3 & \pm 4.67 \\
\hline Brushtail possum & $99.4 \pm$ & $99.7 \pm .96$ & 100.5 .9 & \pm 1.81 \\
\hline Tiger quoll & $99.7 \pm$ & $99.6 \pm .31$ & 99.1 & \pm 1.43 \\
\hline Mean & $99.3 \pm$ & $100.5 \pm .37$ & 98.7 & \pm .92 \\
\hline
\end{tabular}

Note. The period over which the $\dot{\mathrm{V}}_{2}, \dot{\mathrm{V}}_{\mathrm{CO}_{2}}$, and EWL were calculated was kept the same for the comparison of continuous-sampling data with each interrupted data set (i.e., 21, 60, and $36 \mathrm{~min}$ ). Values are mean \pm SE.

${ }^{a}$ Indicates a significant difference from results under continuous (20-s) sampling.

sampling regimes could result from differences in the sampling period over which the mean minimum for an experiment was calculated (i.e., 20, 21, 36, or $60 \mathrm{~min}$ ) or from differences in the sampling frequency (i.e., $20 \mathrm{~s}$ or 3, 6, or $12 \mathrm{~min}$ ).

Increasing the period, and thus the number of data points, over which a mean minimum value is calculated must increase the mean minimum value, as successively higher values are included as the calculation period lengthens (Hayes et al. 1992). This was evident from the significant increases for continuously sampled data in 21-, 36-, and 60-min mean minimums compared with a 20 -min mean (Table 2). Even one additional minute of sampling results in a small but significant increase in the mean minimum value; longer periods result in larger increases. Longer periods for calculating mean minimum values are also more likely to include periodic bouts of alertness and activity, which increases the estimates of BMR and SEWL. As expected, the greater the variance of the data during the period over which the average is calculated, the greater the effect of the period over which the mean is calculated.

One drawback of an interrupted sampling regime is that less frequent sampling necessitates either a longer mean calculation period or a reduced number of data points included in the mean (e.g., sampling every 3 min provides seven values for a 21-min mean, sampling every 6 min provides 10 values for a 60 -min mean, and sampling every 12 min provides three values for a 36-min mean). Some trade-off is required to maximize the number of data points collected and to minimize the required calculation period. There is, however, a minimum sampling period over which a mean should be calculated. Calculated BMR and SEWL should be sustainable physiological states, and transient lower values (e.g., resulting from positional or postural changes within the metabolic chamber or brief periods 
of anapnea) must be avoided. The 95\% equilibrium period of the metabolic system (see Lasiewski et al. 1966) is also an important consideration. Hayes et al. (1992) and Withers (2001) discuss the determination of the period over which the mean should be calculated.

Holding the period over which the mean minimum was calculated constant and lowering the sampling frequency (and therefore reducing the number of data points used to calculate the mean) revealed that all three sampling intervals tested (3, 6 , and $12 \mathrm{~min}$ ) led to an underestimation of BMR (both $\dot{\mathrm{V}}_{2}$ and $\dot{\mathrm{V}}_{\mathrm{CO}_{2}}$ ) but did not influence calculation of SEWL, compared with continuous sampling (Table 3). This is important, as it indicates that sampling frequency per se influences estimates of BMR and that differences are not just an artifact of differences in the period over which the mean is calculated. Clearly, interrupted sampling regimes result in estimates of BMR statistically different from those under continuous sampling regimes, consistently underestimating BMR. Interestingly, EWL was not affected by sampling frequency, presumably because water vapor tends to have longer washout periods than other gases, and this may smooth RH changes within the chamber and reduce sampling-frequency effects.

Comparison of an essentially continuous sampling regime with various interrupted sampling regimes for flow-though respirometry has revealed that sampling regime has a significant influence on estimation of standard physiological variables. Differences in sampling regime result from differences in sampling frequency, which underestimate BMR, and differences in the sampling period over which the mean minimal values for an experiment are calculated, with longer periods overestimating BMR and SEWL. For the 6-min/60-min regime, underestimation by the 6-min sampling frequency was not sufficient to overcome overestimation by the 60 -min sampling period, resulting in an overall overestimation of BMR and EWL. For the 3-min/21-min regime, $\dot{\mathrm{V}}_{2}$ was underestimated because of underestimation by sampling frequency (the overestimation from the sampling period effect was too small to counteract this). For the 12-min/36-min regime, underestimation resulting from sampling frequency was almost exactly counteracted by the 36min sampling period calculation, with the overall estimate of BMR and SEWL statistically indistinguishable from that of the continuous sampling regime.

We have demonstrated that sampling regime has a statistically significant influence on the estimation of standard physiological variables, such as BMR and SEWL, and conclude that the use of switching systems, which necessitate interrupted sampling regimes, are best avoided if optimal data collection is to be achieved. However, variation in the period over which the mean is calculated can mathematically offset or outweigh this underestimation, resulting in values similar to those from a continuous regime or even an overestimate of physiological variables. Despite the high level of significance, the magnitudes of the actual differences between sampling regimes were generally small, mostly $<5 \%$ but sometimes $>12 \%$. To put these sampling errors in context, miscalculation of $\dot{\mathrm{V}}_{2}$ by ignoring the dilution effect of $\mathrm{CO}_{2}$ produces errors of $18 \%-25 \%$, assuming a res- piratory exchange ratio (RER) of 0.85 rather than measuring the actual RER (or absorbing excurrent $\mathrm{CO}_{2}$ ) creates errors of $0 \%-5 \%$, and converting $\dot{\mathrm{V}}_{2}$ to units of energy consumption (i.e., kJ) by assuming an RER of 0.8 instead of measuring the actual RER can result in errors of up to $0.6 \%$ (see Withers 2001). Generally, the effects of miscalibration of equipment (e.g., flowmeters, gas analyzers) on the determination of $\dot{\mathrm{V}}_{2}$, $\dot{\mathrm{V}} \mathrm{CO}_{2}$, and EWL are small and proportional to the magnitude of the miscalibration (Withers 2001). Perhaps one of the largest and most commonly occurring sources of error in the determination of standardized physiological variables is an insufficient experimental duration (Cooper and Withers 2009). More than half of the current BMR data for small marsupials are likely to be overestimated by $15 \%-28 \%$ and three-quarters of the SEWL data to be overestimated by $45 \%$ because of insufficient experimental duration (Cooper and Withers 2009). Compared with these sources of error, the error from an interrupted sampling regime appears to be low to intermediate. Although continuous sampling is the preferred sampling regime for open-flow respirometry studies, if time and cost are prohibitive, then judicious use of a switching system to measure a sufficient sample size of individuals over sufficiently long experimental periods will result in smaller errors than measuring individuals continuously for short durations.

\section{Acknowledgments}

We thank Malcolm and Valerie Douglas and staff at the Malcolm Douglas Wildlife Park; Helen Robinson and staff of the Australian Section at Perth Zoo; Chris Dickman and staff at Arthursleigh Farm and the University of Sydney; Adam Munn and Kylie, Allen, and Allirah Hill, Scott and Graham Thompson, Ariovaldo Cruz-Neto and his students, and Bill Buttemer for providing us with accommodation, laboratory space, access to animals or trapping sites, advice, or assistance. We are grateful to Shane Maloney, Claire McArthur, and Bill Buttemer for the loan of electronic equipment and animal traps. We thank Fritz Geiser for his constructive comments on the manuscript. This study was supported by an Australian Research Council Discovery grant and is manuscript CEDD52-2009 of the Centre for Ecosystem Diversity and Dynamics, Curtin University.

\section{Literature Cited}

Boratyński Z. and P. Koteja. 2009. The association between body mass, metabolic rates, and survival of bank voles. Funct Ecol 23:330-339.

Bush N.G., M. Brown, and C.T. Downs. 2008. Seasonal effects on thermoregulatory responses of the rock kestrel, Falco rupicolis. J Therm Biol 33:404-412.

Buttemer W.A. and L.B. Astheimer. 2000. Testosterone does not affect basal metabolic rate or blood parasite load in captive male white-plumed honeyeaters Lichenostomus penicillatus. J Avian Biol 31:479-488.

Chappell M.A. and R.C. Roverud. 1990. Temperature effects 
on metabolism, ventilation, and oxygen extraction in a Neotropical bat. Respir Physiol 81:401-412.

Cooper C.E. and P.C. Withers. 2008. Allometry of evaporative water loss in marsupials: implications of the effect of ambient relative humidity on the physiology of brushtail possums (Trichosurus vulpecula). J Exp Biol 211:2759-2766.

- 2009. Effects of measurement duration on the determination of basal metabolic rate and evaporative water loss of small marsupials: how long is long enough? Physiol Biochem Zool 82:438-446.

Cooper C.E., P.C. Withers, and A.P. Cruz-Neto. 2009. Metabolic, ventilatory, and hygric physiology of the gracile mouse opossum (Gracilinanus agilis). Physiol Biochem Zool 82:153162.

Dawson T.J., C.E. Blaney, A.J. Munn, A. Krockenberger, and S.K. Maloney. 2000. Thermoregulation by kangaroos from mesic and arid habitats: influence of temperature on routes of heat loss in eastern grey kangaroos (Macropus giganteus) and red kangaroos (Macropus rufus). Physiol Biochem Zool 73:374-381.

Depocas F. and J.S. Hart. 1957. Use of the Pauling oxygen analyzer for measurement of oxygen consumption of animals in open-circuit systems and in short-lag, closed-circuit apparatus. J Appl Physiol 10:388-392.

Doucette L.I. and F. Geiser. 2008. Seasonal variation in thermal energetics of the Australian owlet-nightjar (Aegotheles cristatus). Comp Biochem Physiol A 151:615-620.

Downs C.T. and M. Brown. 2002. Nocturnal heterothermy and torpor in the malachite sunbird (Nectarinia famosa). Auk 119:251-260.

Elia M., T. McDonald, and A. Crisp. 1986. Errors in measurements of $\mathrm{CO}_{2}$ with the use of drying agents. Clin Chim Acta 158:237-244.

Gallivan G.J. 1992. What are the metabolic rates of cetaceans? Physiol Zool 65:1285-1297.

Hayes J.P., J.R. Speakman, and P.A. Racey. 1992. Sampling bias in respirometry. Physiol Zool 65:604-619.

Hemmingsen A.M. 1950. The relationship of standard (basal) energy metabolism to total fresh weight of living organisms. Rep Steno Mem Hosp Cph 4:1-58.

Hill R.W. 1972. Determination of oxygen consumption by use of the paramagnetic oxygen analyser. J Appl Physiol 33:261263.

Holloway J.C. and F. Geiser. 2001. Seasonal changes in the thermoenergetics of the marsupial sugar glider Petaurus breviceps. J Comp Phyiol B 171:643-650.

IUPS Thermal Commission (Commission for Thermal Physiology of the International Union of Physiological Scientists). 2003. Glossary of terms for thermal physiology. 3rd ed. J Therm Biol 28:75-106.

Kleiber M. 1932. Body size and metabolism. Hilgardia 6:315353.

Koteja P. 1996. Measuring energy metabolism with open-flow respirometric systems: which design to choose? Funct Ecol 10:675-677.

Larcombe A.N. 2002. Effects of temperature on metabolism, ventilation, and oxygen extraction in the southern brown bandicoot Isoodon obesulus (Marsupialia: Peramelidae). Physiol Biochem Zool 75:405-411.

Lasiewski R.C., A.L. Acosta, and M.H. Bernstein. 1966. Evaporative water loss in birds. I. Characteristics of the open flow method of determination, and their relation to estimates of thermoregulatory ability. Comp Biochem Physiol 19:445457.

Lighton J.R.B. 2008. Measuring Metabolic Rates: A Manual for Scientists. Oxford University Press, New York.

Maddocks T.A. and F. Geiser. 1997. Energetics, thermoregulation, and nocturnal hypothermia in Australian silvereyes. Condor 99:104-112.

McKechnie A.E. and B.G. Lovegrove. 1999. Circadian metabolic responses to food deprivation in the black-shouldered kite. Condor 101:426-432.

- 2001. Thermoregulation and the energetic significance of clustering behavior in the white-backed mousebird (Colius colius). Physiol Biochem Zool 74:238-249.

McNab B.K. 1997. On the utility of uniformity in the definition of basal rate of metabolism. Physiol Zool 70:718-720.

. 2003. Sample size and the estimation of physiological parameters in the field. Funct Ecol 17:82-86.

. 2005. Uniformity in the basal metabolic rate of marsupials: its causes and consequences. Rev Chil Hist Nat 78: 183-198.

- 2006. The relationship among flow rate, chamber volume, and calculated rate of metabolism in vertebrate respirometry. Comp Biochem Physiol A 145:287-294.

Merola-Zwartjes M. 1998. Metabolic rate, temperature regulation, and the energetic implications of roost nest in the bananaquit (Coereba flaveola). Auk 115:780-786.

Newman R.E., W.L. Bryden, E. Fleck, J.R. Ashes, W.A. Buttemer, L.H. Storlien, and J.A. Downing. 2002. Dietary n-3 and n6 fatty acids alter avian metabolism: metabolism and abdominal fat deposition. Brit J Nutr 88:11-18.

Rencher A.C. 1995. Methods of Multivariate Analysis. Wiley, New York.

Schmidt-Nielsen K. 1984. Scaling: Why Is Animal Size So Important? Cambridge University Press, New York.

Song X. and F. Geiser. 1997. Daily torpor and energy expenditure in Sminthopsis macroura: interactions between food and water availability and temperature. Physiol Zool 70:331337.

Walsberg G.E. and B.O. Wolf. 1995. Variation in the respiratory quotient of birds and implications for indirect calorimetry using measurements of carbon dioxide production. J Exp Biol 198:213-219.

White C.R., S.J. Portugal, G.R. Martin, and P.J. Butler. 2006. Respirometry: anhydrous Drierite equilibrates with carbon dioxide and increases washout times. Physiol Biochem Zool 79:977-980.

Withers P.C. 1977. Measurement of $\dot{\mathrm{V}}_{2}, \dot{\mathrm{V}}_{\mathrm{CO}_{2}}$ and evaporative water loss with a flow-through mask. J Appl Physiol 42:120123. 
1992. Comparative Animal Physiology. Saunders College, Philadelphia.

2001. Design, calibration, and calculation for flowthrough respirometry systems. Aust J Zool 49:445-461.

Withers P.C. and C.E. Cooper. 2009. Thermal, metabolic, and hygric physiology of the little red kaluta, Dasykaluta rosamondae (Dasyuromorphia: Dasyuridae). J Mammal 90:752-760.

Withers P.C., C.E. Cooper, and A. Larcombe. 2006. Environmental correlates of physiological variables in marsupials. Physiol Biochem Zool 79:437-453. 